\title{
Thermal Analysis and Characterization of Some Cellulosic Fabrics Dyed by a New Natural Dye and Mordanted with Different Mordants
}

\author{
S.F. Ibrahim (Corresponding author) \\ Textile Metrology Lab, National Institute for Standards, Giza, Egypt \\ E-mail: drsaherfawzy09@hotmail.com \\ E. S. El-Amoudy \\ Girls College for education, Jeddah-Kingdom of Saudi \\ K. E. Shady \\ Textile Metrology Lab, National Institute for Standards, Giza, Egypt
}

Received: February 22, 2011 Accepted: March 12, 2011 doi:10.5539/ijc.v3n2p40

\begin{abstract}
A new natural dye was extracted from Bisham plant then applied to cotton and linen fabrics. The thermal stability of these fabrics in their blank state then dyed by this natural dye (Commiphora-gileadensis), and then mordanted by different mordants that are; Alum (Potassium and Aluminum Sulfate) $\mathrm{AL}_{2} \mathrm{~K}_{2}\left(\mathrm{SO}_{4}\right) \cdot 24 \mathrm{H}_{2} \mathrm{O}$ Chrome (Potassium di-Chromate $\mathrm{K}_{2} \mathrm{Cr}_{2} \mathrm{O}_{7}$ ) and Ferrous sulfate $\left(\mathrm{FeSO}_{4} \cdot 7 \mathrm{H}_{2} \mathrm{O}\right)$ which were applied separately. Thermal analysis is a convenient, useful and reproducible method for characterizing complex organic materials. Thermo-gravimetric analysis (TGA), its differential (DTG) and differential scanning calorimetry (DSC) were used to evaluate the effect of mordanting cotton and linen fabric on their thermal behaviour. These techniques can distinguish between different fiber generic types and between different mordants applied to their dyed fabrics. It was possible to detect the presence of the mordant component when present in small proportions. Although cotton and linen fabrics produce the same DTG peaks, they can be differentiated as their main endothermic peaks occur at significantly different temperature (about $348,339^{\circ} \mathrm{C}$ respectively).Also, linen fabric produces an asymmetrical deep peak compared with the sharper, more symmetrical peak of cotton.
\end{abstract}

Keywords: Commiphora-gileadensis, Cellulosic fabrics, Thermal stability, Thermo-gravimetric analysis (TGA), Differential scanning calorimetry (DSC)

\section{Introduction}

The most used materials for textile manufacture are cotton, linen (cellulose based materials). Linen composition has about $2 \%$ of lignin, so the behaviour of the two fabrics is different. The dye-ability and light fastness of the dyes used for these two fabrics are influenced by many factors, such as: chemical and physical state of both the dye and the fabric, additives in the dyeing bath, environmental conditions and the source and intensity of the light source [P.Bhama Iyer, 1976; M.S. Robert, 1996]. Different mordant are used before and after or during cellulose fabric dyeing to decrease photodegradation, acid hydrolysis, oxidation and biodegradation. Mordants were firstly used to obtain different shades from the same dye.

It was found that the mordant is more important than the dye itself [E.M.Othman, 2001; E.S.Al-Amoudi, 2009] the colour fastness of the dyed materials is determined according to the mordant type, concentration, method of application, $\mathrm{pH}$ of the dyeing media and nature of both substrate and dye used. A link is formed between dyestuff and fabric when the mordant is fixed on the fiber and also combine with the dyestuff. This allows a certain dye with no affinity for the fabric to be fixed.

The main objective of the present research is to evaluate the effect of different mordants-namely, Alum (Potassium and Aluminum Sulfate) $\mathrm{AL}_{2} \mathrm{~K}_{2}\left(\mathrm{SO}_{4}\right) \cdot 24 \mathrm{H}_{2} \mathrm{O}$, Chrome (Potassium di-Chromate $\mathrm{K}_{2} \mathrm{Cr}_{2} \mathrm{O}_{7}$ ) and Ferrous sulfate $\left(\mathrm{FeSO}_{4} \cdot 7 \mathrm{H}_{2} \mathrm{O}\right)$ - on the thermal behaviour of dyed cotton and linen fabrics using TGA,DTGA and DSC. Since natural fibers from plants, such as cotton and flax, when heated decompose and totally degrade losing their main features, improving their stability is highly required. In polymer science thermal methods of analysis have 
found important applications. Many researchers [T. Joseph, 1993; M. V. Ramiah, 2003] have stated that the power of these techniques is only clearly demonstrated when thermally induced physical transitions, such as fusion and crystallization, are affected. The graph of mass against temperature thermally induces mass changes, such as; drying, chemical reaction, degradation and volatilization to be detected. Many authors have expressed the opinion that TG has potential as a technique for fiber degradation [A.K. BledzKi, 1997]. They have found that, the temperature at which mass loss starts and proceeds at its fastest rate is unique for a given polymer and this technique can therefore be used for characterization purpose since it reflects reaction which occurs at the molecular level of the material. DSC allows a rapid detection and measurement of the physical and chemical changes that a polymer undergoes when subjected to heating [D. Giron, 1995].

Natural dyes mainly include those from vegetable sources -like leaves, stems, roots, barks and flowers of plantand those from animal sources -like Lac from Laccifera insect, Kerms dye from Kermes Vermilio Planchoninsect and Cochineah dye from Dactylopius Coccus Costa. In addition, there are many mineral colouring matters produce natural dye effects on fabric [M. R. Seonaid, 1973].

In this paper, it is reported that, thermo-gravimetric analysis (TGA), its differential (DTG) and differential scanning calorimetry (DSC) are very useful to evaluate the effect of mordanting cotton and linen fabrics on their thermal behaviour. These techniques can distinguish between different fiber generic types and between the same dyed and mordanted fabrics.

\section{Experimental Work}

\subsection{Materials \& Chemicals}

I) The fabrics used throughout this study were:

1- Pure cotton fabric: $(100 \%)$, the weight was $120 \mathrm{~g} / \mathrm{m}^{2}$, thickness was $0.261 \mathrm{~cm} / \mathrm{mm}$, number of yarns $/ \mathrm{cm}$ in warp direction was 43 , and in weft direction was 31 .

2- Pure linen fabric: $(100 \%)$, the weight was $90 \mathrm{~g} / \mathrm{m}^{2}$, thickness was $0.425 \mathrm{~cm} / \mathrm{mm}$, number of yarns/ $\mathrm{cm}$ in warp direction was 22, and in weft direction was 18 .

These fabrics were kindly supplied by Golden Tex Company, Egypt, and purified in laboratory by scouring with a solution containing $2 \mathrm{~g} / \mathrm{l}$ of non-ionic detergent with liquor ratio $1: 50$ at $60{ }^{\circ} \mathrm{C}$ for 15 minutes. Finally, the samples are thoroughly washed with water, and then dried at ambient conditions.

II) The dye used was a natural dye named Commiphora-gileadensis which was derived from Balsan Makki or Bisham plant.

III) Mordants were; Alum (Potassium and Aluminum Sulfate) $\mathrm{AL}_{2} \mathrm{~K}_{2}\left(\mathrm{SO}_{4}\right) \cdot 24 \mathrm{H}_{2} \mathrm{O}$, Chrome (Potassium di-Chromate $\left.\mathrm{K}_{2} \mathrm{Cr}_{2} \mathrm{O}_{7}\right)$ and Ferrous sulfate $\left(\mathrm{FeSO}_{4} \cdot 7 \mathrm{H}_{2} \mathrm{O}\right)$, all were used in a pure state.

\subsection{Testing and Analysis}

\section{b.1) Dye Extraction Procedure:}

Figure (1) shows the DSC of the used dye. This dye was extracted from Balsan Makki or Bisham plant which has red flowers and largely dispersed in the kingdom of Saudi Arabian and recently in parts of Egypt, as follows:

1- $20 \mathrm{~g}$ of the dye was dissolved in $100 \mathrm{ml}$ distilled water to get a concentrated dye solution, then left 24 hours for complete extraction.

2- The dye liquor was slowly heated till $100{ }^{\circ} \mathrm{C}$, and then left at this temperature for one hour to get the required quantity of the extracted dye.

3- The extracted dye was cooled, then filtrated to drain of undesired portions.

4- Finally, the dye liquor was measured again and it was standed to its original level by adding distilled water.

b.ii) Dyeing and Mordanting Method:

The samples under test were separately dyed by the pre-extracted dye in a laboratory dyeing apparatus using the conventional exhaustion dyeing method [J. Jonson Edition, 1990]. Different mordants were added to the dye bath separately with a fixed concentration that is: Alum (Potassium and Aluminum Sulfate) $\mathrm{AL}_{2} \mathrm{~K}_{2}\left(\mathrm{SO}_{4}\right) \cdot 24 \mathrm{H}_{2} \mathrm{O}$ of concentration $5 \mathrm{~g} /$ liter- Chrome (Potassium di-Chromate $\mathrm{K}_{2} \mathrm{Cr}_{2} \mathrm{O}_{7}$ ) of concentration $2 \mathrm{~g} /$ liter - Ferrous sulfate $\left(\mathrm{FeSO}_{4} .7 \mathrm{H}_{2} \mathrm{O}\right)$ of concentration $5 \mathrm{~g} /$ liter. All dyeings were carried out using $\mathrm{pH}=7$, at temperature $100^{\circ} \mathrm{C}$ for 60 minutes and a liquor ratio of 1:40.Finally the dyed samples were thoroughly washed then dried at ambient conditions.

b.iii) Thermal Analysis 
Thermogravimetric analysis (TGA) was performed on a TGA-50 Shimadzu instrument at a flow rate of 30 $\mathrm{ml} / \mathrm{min}$. under nitrogen atmosphere with temperature range from room temperature to $650^{\circ} \mathrm{C}$, where the thermal behaiour of all the samples were investigated using thermo-gravimetric analysis. A Shimadzu DSC-50 Japan Analyzer was used for differential scanning colorimetric. DSC experiments were carried out on all samples with heating rate $10^{\circ} \mathrm{C} / \mathrm{min}$., using dry nitrogen $\left(\mathrm{N}_{2}\right)$ as a carrier gas and at a flow rate of $30 \mathrm{ml} / \mathrm{min}$. Samples were repeated three times to insure repeatability. Scans are started at temperature $30{ }^{\circ} \mathrm{C}$ to a final temperature of 750 ${ }^{\circ} \mathrm{C}$.

\section{Results and Discussions}

Thermal analysis techniques (TG, DTG and DSC) were used to study the effect of different mordants on cotton and linen fabrics dyed by a new natural dye (Commiphora-gileadensis). The TG, DTG and DSC curves of these samples are listed in tables (1-4) and presented by figures (2-5) respectively.

Thermogravimetry analysis (TGA) provides quantitative information on weight change during heating process [H. S. Sharma, 1988]. Figure (2) shows TGA curves for blank cotton, dyed cotton and dyed cotton mordanted by Alum (Potassium and Aluminum Sulfate) $\mathrm{AL}_{2} \mathrm{~K}_{2}\left(\mathrm{SO}_{4}\right) \cdot 24 \mathrm{H}_{2} \mathrm{O}$, Chrome (Potassium di-Chromate $\mathrm{K}_{2} \mathrm{Cr}_{2} \mathrm{O}_{7}$ ) and Ferrous sulfate $\left(\mathrm{FeSO}_{4} .7 \mathrm{H}_{2} \mathrm{O}\right)$. The recorded thermogravimetric plots for all cotton samples show two degradation steps which suggest the co-existence of more than one degradation process. The lower temperature loss (i.e., the first step) may correspond to the breaking of water linkage, and the second may correspond to the degradation of the whole polymer cotton and /or the dye, mordant). The second loss is the most important both in rate of weight loss and in total weight loss. In the case of pure polymeric fabric, the first step may be assigned to the thermo-oxidative degradation of the fabrics which transformed to the carbonaceous residues. These may decompose during the second step of the degradation process [T. Joseph, 1993].

Table (1) shows the change in temperature at which mass loss started, when the peaks occurred and that temperature at which the mass loss process was subjectively judged to be complete. In accordance with the literature [Z. M Sefain, 1994], it has been established that there is no degradation taking place until $200^{\circ} \mathrm{C}$. Above this temperature, thermal stability is gradually decreasing and decomposing of the fibers occurs.

Derivative thermogravimetric analysis (DTGA) traces for blank cotton, dyed cotton with natural dye (Commiphora-gileadensis) without any mordants, cotton dyed with natural dye (Commiphora-gileadensis) and mordanted with alum, ferrous sulfate and chrome, are shown in figure (3). Table (1) indicates the values of the glass transition temperature (Tg) and the decomposition temperature $\left(T_{d}\right)$ and their percentage changes for the samples detected from figure (3). It may be mentioned that the decomposition temperature for cellulosic fabrics depends on their molecular weight and purity [Kennedy J.F., 1994]. In addition, the decomposition temperature $\left(\mathrm{T}_{\mathrm{d}}\right)$ is affected by polymer morphology and high crystallinity of a polymer means high decomposition temperature [P. Elisabetta, 2005; Rosen, S.L., 1993].

By following the weight loss during the decomposition range for the examined cotton fabrics as assigned through table 1, it is clear that the samples of the dyed cotton mordanted with alum has the lowest value of loss, which means that cotton samples becomes more thermally stable when using alum as a mordant after dyeing.

On the other hand, the assigned values of weight loss for the examined linen fabrics are shown in table 2, where, it is noticed that the samples dyed and mordanted by chrome lost the minimum weight $(5.714 \mathrm{mg})$, while that of dyed linen samples without mordant, the maximum weight loss is $(7.69 \mathrm{mg})$. The calculated area for the second endothermic peaks of linen fabrics which is represented by the heat of fusion are the highest one for linen fabric dyed and mordanted by alum $(-90.86 \mathrm{~J} / \mathrm{g})$, then that of dyed linen without mordant, then that of the blank linen fabrics followed by linen fabrics dyed and mordanted by ferrous sulfate and the lowest value of heat of fusion is that of dyed linen mordanted with chrome.

From the DTG curves for the examined cotton samples (figure 3), it is observed that the second endothermic peak is deeper in the case of dyed cotton than that of the blank cotton. No more endothermic peak observed in both after the appearance of this second one, but in case of cotton dyed and mordanted by alum a new third shallow endothermic peak appeared at $\left(562^{\circ} \mathrm{C}\right)$ and more weight is lost, which means that decomposition still continue due to the presence of alum mordant in the fabric.

With respect to the cotton fabrics dyed and mordanted with chrome,a third very sharp endothermic peak at $\left(467.22^{\circ} \mathrm{C}\right)$ occurred at which weight of $2.094 \mathrm{mg}$ is lost. This peak is nearby the second one. The second endothermic peak has small shoulder at its left side and another bigger one at its right side which may show the presence of impurities in the sample [V.Silvia, 2004; W. Veerawat, 1978]. Both the second and the third peaks are the broadest and the deepest in the investigation. New endothermic peak is appeared at $\left(396.38{ }^{\circ} \mathrm{C}\right)$ in the 
DTG of cotton fabrics dyed and mordanted with ferrous sulfate, which is less in depth than that of chrome but deeper than that of alum. The second endothermic peak is sharp, deep and has an unnoticeable shoulder at its right side.

The thermal behaviour of linen fabrics under investigation is shown in figure (4). All of the samples have two endothermic peaks, its temperature range are shown in (table 6). The dyed linen fabrics has a second endothermic peak at $\left(345.72{ }^{\circ} \mathrm{C}\right)$, this peak is sharper and deeper than that of the blank one which occurred at $\left(339.03{ }^{\circ} \mathrm{C}\right)$. It is observed that the linen fabrics dyed and mordanted by alum has no third endothermic peak looks like that of cotton. The second peak is boarder but less in depth than that of the blank linen. Linen samples dyed and mordanted with chrome have a clear wide endothermic peak, no third peak as in the case of the examined cotton samples. The second endothermic peak (decomposition peak) is at $\left(343^{\circ} \mathrm{C}\right)$, deep, wide like that for samples dyed and mordanted with alum. A small unremarkable shoulder appeared at its left. In the case of dyed linen samples and mordanted with ferrous sulfate, a new clear, broad, deep third endothermic peak is appeared at $\left(428^{\circ} \mathrm{C}\right)$. Its second endothermic peak at $\left(337^{\circ} \mathrm{C}\right)$ is sharper, deeper but less in width than that of alum or chrome.

Table (3) and figure (8) show the changes in DSC of cotton samples in ( $\mathrm{mW}$ ) where maximum value is recorded for blank undyed cotton fabrics $(371.07 \mathrm{mw})$ and minimum value is for dyed cotton mordanted with chrome (325.48mW). While DSC values of linen fabrics shown in table 5 and figure 10 show that maximum value is recorded for blank dyed linen without mordant $(366.46 \mathrm{~mW})$ and minimum value is for blank undyed (341.21 $\mathrm{mW}$ ). Table (4) and figure (9) show the changes in heat released values of cotton fabrics where maximum value is recorded for blank dyed cotton without mordant $(-668.78 \mathrm{~mJ})$ and minimum value is for dyed cotton fabrics and mordanted with ferrous sulfate $(-105.24 \mathrm{~mJ})$. The heat released values $(\mathrm{mJ})$ of different cotton fabrics having negative values indicating [D. Giron, 1995] endothermic reactions occurrence.

Table (6) and figure (11) show the changes in heat released values of linen fabrics where maximum value is recorded for dyed linen with alum(-708.00 $\mathrm{mJ})$ and minimum value is for dyed linen dyed and mordanted with ferrous sulfate $(-95.58 \mathrm{~mJ})$.Also, the heat released values $(\mathrm{mJ})$ of different linen fabrics having negative values indicating endothermic reactions occur.

From figure (3), it is noticed that the decomposition temperature of blank cotton fabric has the highest value (371 ${ }^{\circ} \mathrm{C}$ ), while it is the same for both dyed cotton fabrics and that dyed and mordanted by alum $(364.60,365.32)^{\circ} \mathrm{C}$, that dyed and mordanted by chrome is lower $\left(342^{\circ} \mathrm{C}\right)$ and the lowest one is that for ferrous sulfate $\left(325.48^{\circ} \mathrm{C}\right)$. The onset temperature is equal for both blank cotton and that dyed and mordanted with alum while that dyed fabric only has onset temperature of $336.81{ }^{\circ} \mathrm{C}$, and is nearly equal to that of dyed fabric mordanted with chrome. The lowest one is also that for ferrous sulfate.

The end set temperature of blank cotton fabric is the highest $\left(390^{\circ} \mathrm{C}\right)$ while that for dyed fabric only is equal to that of fabric dyed and mordanted with alum $\left(387.58^{\circ} \mathrm{C}\right)$. The end set temperature of both fabrics dyed and mordanted with chrome and ferrous sulfate $\left(375.99^{\circ} \mathrm{C}\right)$.

The calculated area for the second endothermic peak of the investigated cotton fabrics takes the order: dyed cotton without mordant $>$ blank cotton $>$ dyed cotton mordanted with alum $>$ dyed cotton mordanted by ferrous sulfate $>$ cotton dyed and mordanted by chrome.

Many of the dyes increased the oxygen index of the dyed fabric over that of the undyed fabric [N.A. El-Zaher, 2005]. The reduction of the dyed cotton flammability was attributed to the covalent bonding of the dye to the anhydroglucose rings of the cellulose molecule thus interfering with the pyrolysis of cellulose to levoglucosan.

It was observed [A Noureddine., 2009] that cotton decomposed at $\left(375^{\circ} \mathrm{C}\right)$ producing $12.5 \%(\mathrm{w} / \mathrm{w} \%)$ of char residues, while dyed cotton with reactive dyes decomposed at $325{ }^{\circ} \mathrm{C}$ producing $37.3 \%(\mathrm{w} / \mathrm{w} \%$ ) of char residues. The temperature at which rapid weight loss started was also lowered by the dye. These results indicate that when applied at a high constant ratio, the dye lowered the decomposition temperature of cotton [C. M.Tian, 1999 ; B. Babiker, 2007], and shifted the path of the reaction towards the formation of more solid residues.

\section{Conclusions}

1-A new natural dye was applied to cotton and linen fabrics, which helps avoiding disadvantages of synthetic dyes

2-Three mordants: alum, chrome and ferrous sulfate were used to fix the dye to the fabric.

3-Thermal analysis methods such as differential scanning calorimetry (DSC) and thermal analysis gravimetery (TGA) and its derivative were employed to study the change in the thermal stability of the fabrics under investigation. 
4- An insight in understanding the structural changes occurring when these cellulosic fabrics were mordanted after dyeing was reported.

5-Regarding the cellulosic decomposition, the peak shifts to higher temperature than unmordanted dyed fabrics. The shifts can be explained assuming that the mordanted cellulose has better thermal stability due to the presence of mordant.

6-These observations suggest that the thermal analysis data contain information related to the structural properties of different materials, and can be used to predict properties that are directly related to their physical performance as well as their thermal degradation parameters.

\section{References}

A Noureddine., C.Luis \& H. Eric. (2009). Thermogravimetric analysis of developing cotton fibers. Thermochimica Acta, In Press, Corrected Proof, Available online 30 September.

A.K. BledzKi, \& J.Gassen. (1997). Natural Fiber Reinforce Plastics. Hand book of Engineering Polymeric Materials, Marcel Dekker Publishers, NewYork, 810

B. Babiker. (2007). The influence of reactive dyes on the pyrolysis of cotton. Journal of Analytical and Applied Pyrolysis, Vol. 4 No.10, 162-166.

C. M.Tian, Z. H. Shi. H. Y. Zhang, Z. J. R. Xu, \& H. Z. Shi, Guo. (1999). Thermal Degradation of Cotton Cellulose. Journal of Thermal Analysis and Calorimetry, Vol. 55/issue 1, 93-98.

D. Giron. (1995). Thermal analysis and calorimetric methods in the characterization of polymorphs and solvates. Thermochimica Acta, Vol.248, 1-59.

E.M.Othman. (2001). Ph.D. Thesis. Applying Natural dyes on Natural Fabrics and Studying their Diffusion Kinetics and Photo-fading Characteristics, Helwan University, Cairo, Egypt.

E.S.Al-Amoudi \& E.M. Osman. (2009). Optimization of Dyeing Performance of an Eco -Friendly Natural Dye Vervain Barks applied to Silk Fabrics at Different pH Values. RJTA, Vol.13, No.1.

H. S. Sharma., \& K.Kernaghan. (1988). Thermogravimetric analysis of flax fibres. Thermochimica Acta, Vol. 132, 101-109.

J. Jonson Edition. (1990). The Theory of Coloration of Textiles. Society of Dyers and Colorist, Bradford.

Kennedy J.F., Phillips G.O. \& Williams P.A. (1994). Cellulosics: Chemical, Biochemical and Material Aspects. Ells Horwood, Series in Polymer Science and Technology, 135-140.

M. R. Seonaid. (1973). Dyes from plants, copy right by Litton Educational Publishing Inc. 32-34.

M. V. Ramiah. (2003). Thermogravimetric and differential thermal analysis of cellulose, hemicellulose, and lignin. Department of Fisheries and Forestry, Canadian Forestry Service, Forest Products Laboratory, Vancouver, British Columbia. Journal Applied Polymer Science, Vol.51 /issue, 5, 1323 - 133.

M.S. Robert \& X.W. Francis. (1996). Spectrometric Identification of Organic Compounds, Sixth Edition, Vol.27, No.12.

N.A. El-Zaher \& W.G. Osiris. (2005). Study of thermal and structural properties of poly(vinyl alcohol) doped with hydroxyl propyl cellulose. Journal of Applied Polymer Science, vol.96, PP.1-59.

P. Elisabetta, V. Silvia, P.Enrico, M.Alessandro, F.Enrico, L Giogio \& T.Vincenzo. (2005). Thermal analysis and characterization of cellulose grafted with acrylic monomers. ThermochimicaActa, Vol.25/ issues 1-2, 3-179.

P.Bhama Iyer, K.R.Krishna Iyer \& N.B. Patil. (1976). An Infrared Technique for the Quick Analysis of Cotton -Polyester Blends. Journal of Applied Polymer Science, Vol. 20, 59-595.

Rosen, S.L. (1993). Fundamental Principles of Polymeric Materials. John Wiley, New York, NY.C, Second Edition, page 30 .

T. Joseph, Wanna, E. Janine Powell. (1993). Thermal decomposition of cotton cellulose treated with selected salts. Thermochimica Acta, Vol. 226, 257-263.

V.Silvia, P.Elisabetta, L.Giorgio, F.AEnrico, P.Enrico, O.Dagmara, K Halina. \& S. Alina. (2004). Thermal analysis and characterization of cellulose oxidised with sodium methaperiodate, ThermochimicaActa, Vol.418/ issues 1-2, 123-130.

W. Veerawat, Srichatrapimuk and L.S. Cooper. (1978). Infrared thermal analysis of polyurethane block polymers. Journal of Macromolecular Science, Part B: Physics, Vol. 15, Issue 2, 267 - 311. 
Z. M Sefain, M. M. Naoum, H. M. Fadl, \& A. N. El-Wakil. (1994). Thermal behaviour of cyanoethylated cellulose. Thermochimica Acta, Vol. 231, 257-265.

Table 1. The change in weight loss percentage of different cotton fabrics

\begin{tabular}{|c|c|c|c|c|}
\hline \multirow{2}{*}{ Sample name } & \multicolumn{2}{|c|}{ First Stage } & \multicolumn{2}{c|}{ Second Stage } \\
\cline { 2 - 5 } & weight change(mg) & $\begin{array}{c}\text { Loss weight } \\
\text { percentage } \\
(\%)\end{array}$ & $\begin{array}{c}\text { weight } \\
\text { change } \\
(\mathrm{mg})\end{array}$ & $\begin{array}{c}\text { Loss weight } \\
\text { percentage } \\
(\%)\end{array}$ \\
\hline blank cotton undyed & $-4,935$ & 67.88 & -6.477 & 89.09 \\
\hline blank cotton dyed without mordant & $-5,533$ & 74.75 & -7.087 & 95.75 \\
\hline dyed cotton and mordanted with alum & $-4,249$ & 67.00 & -6.27 & 98.65 \\
\hline dyed cotton and mordanted with chrome & $-4,538$ & 61.49 & -7.971 & 97.52 \\
\hline dyed cotton and mordanted with ferrous sulfate & $-4,055$ & 58.38 & -6.798 & 97.86 \\
\hline
\end{tabular}

Table 2. The change in weight loss percentage of different linen fabrics

\begin{tabular}{|c|c|c|c|c|}
\hline \multirow{2}{*}{ Sample name } & \multicolumn{2}{|c|}{ First Stage } & \multicolumn{2}{c|}{ Second Stage } \\
\cline { 2 - 5 } & weight change(mg) & $\begin{array}{c}\text { Loss weight } \\
\text { percentage } \\
(\%)\end{array}$ & $\begin{array}{c}\text { weight } \\
\text { change } \\
(\mathrm{mg})\end{array}$ & $\begin{array}{c}\text { Loss weight } \\
\text { percentage } \\
(\%)\end{array}$ \\
\hline blank linen undyed & -4.94 & 64.99 & -6.28 & 82.65 \\
\hline blank linen dyed without mordant & -5.27 & 67.80 & -7.69 & 98.49 \\
\hline dyed linen and mordanted with alum & -5.89 & 19.40 & -7.25 & 96.39 \\
\hline dyed linen and mordanted with chrome & -4.06 & 17.80 & -5.71 & 91.09 \\
\hline dyed linen and mordanted with ferrous sulfate & -3.57 & 27.70 & -2.14 & 34.49 \\
\hline
\end{tabular}

Table 3. The change in DSC peak energy values $(\mathrm{mW})$ of different cotton fabrics

\begin{tabular}{|c|c|}
\hline Sample number & DSC peak energy values $(\mathrm{mW})$ \\
\hline sample1 & 371.07 \\
\hline sample2 & 364.61 \\
\hline sample3 & 365.32 \\
\hline sample4 & 342.03 \\
\hline sample5 & 325.48 \\
\hline
\end{tabular}

Table 4 . The change in heat released values $(\mathrm{mJ})$ of different cotton fabrics

\begin{tabular}{|c|c|}
\hline Sample number & $\begin{array}{c}\text { Heat released values (mJ) } \\
\text { (-ve values) }\end{array}$ \\
\hline sample1 & 365.58 \\
\hline sample2 & 668.78 \\
\hline sample3 & 358.91 \\
\hline sample4 & 105.24 \\
\hline sample5 & 220.49 \\
\hline
\end{tabular}


Table 5. The change in DSC peak energy values $(\mathrm{mW})$ of different Linen fabrics

\begin{tabular}{|c|c|}
\hline Sample number & DSC peak energy values $(\mathrm{mW})$ \\
\hline Sample 6 & 341.21 \\
\hline Sample 7 & 366.46 \\
\hline Sample 8 & 361.24 \\
\hline Sample 9 & 364.35 \\
\hline Sample 10 & 342.87 \\
\hline
\end{tabular}

Table 6. The change in heat released values (mJ) of different Linen fabrics

\begin{tabular}{|c|c|}
\hline Sample number & $\begin{array}{c}\text { Heat released values (mJ) } \\
\text { (-ve values) }\end{array}$ \\
\hline sample6 & 265.71 \\
\hline sample7 & 517.32 \\
\hline sample8 & 708.73 \\
\hline sample9 & 95.58 \\
\hline sample10 & 144.75 \\
\hline
\end{tabular}

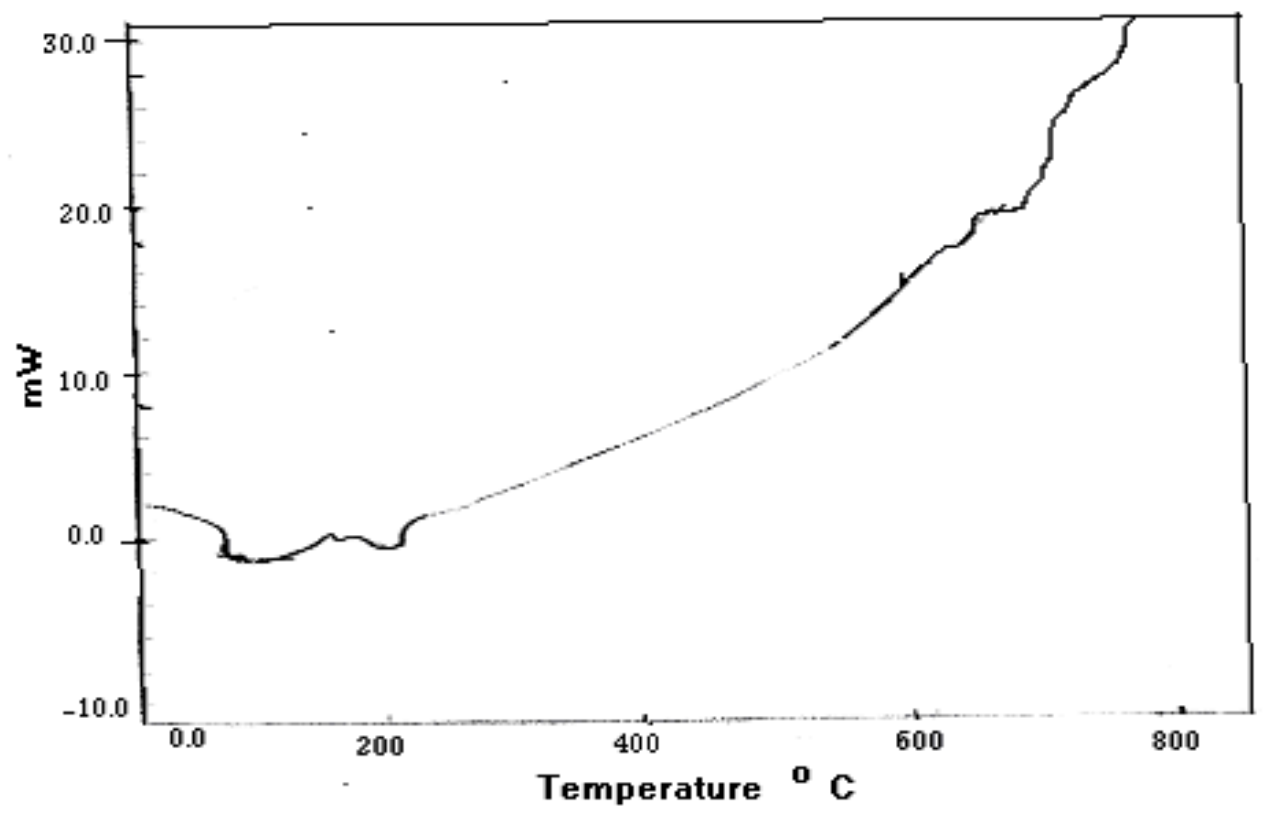

Figure 1. DSC curve of Commiphora-gileadensis natural dye 


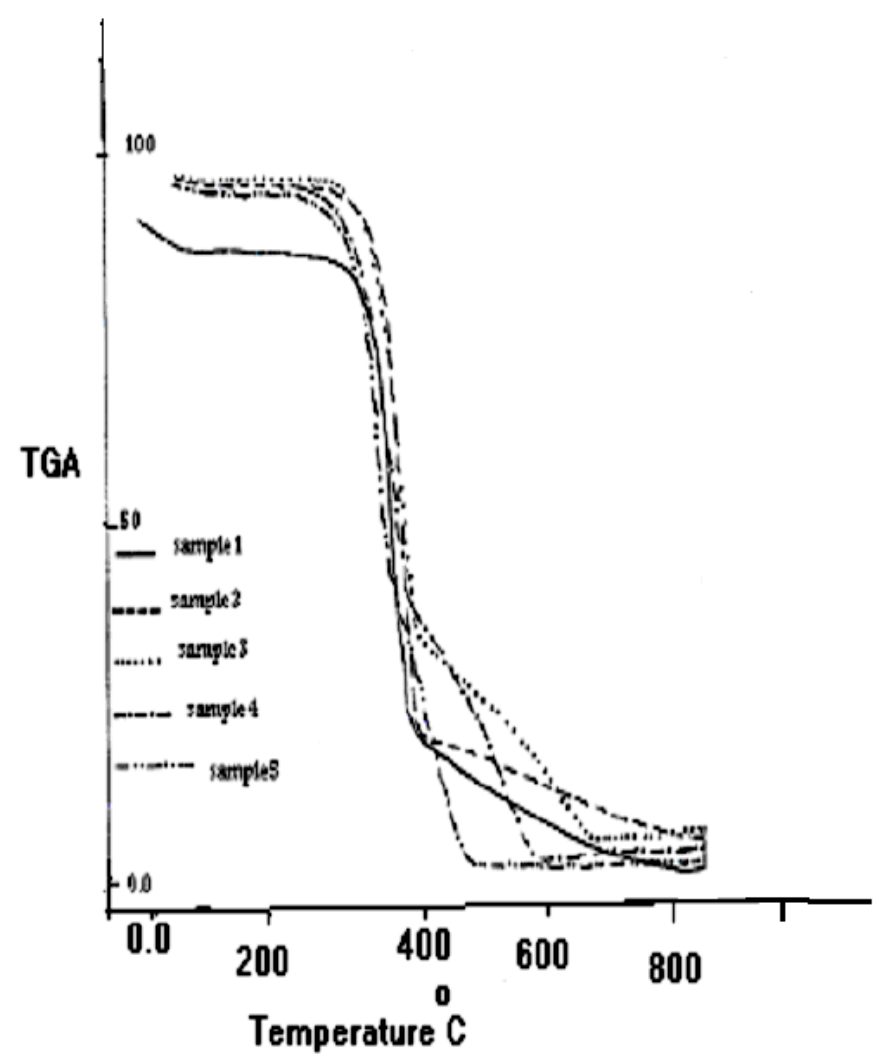

Figure 2. Typical TGA thermograms of cotton fabrics

Where: sample1=blank cotton fabric undyed, sample $2=$ blank cotton fabric dyed without mordant, sample $3=$ cotton fabric dyed with Alum, sample $4=$ cotton fabric dyed with ferrous sulfate, sample $5=$ cotton fabric dyed with Chrome. 


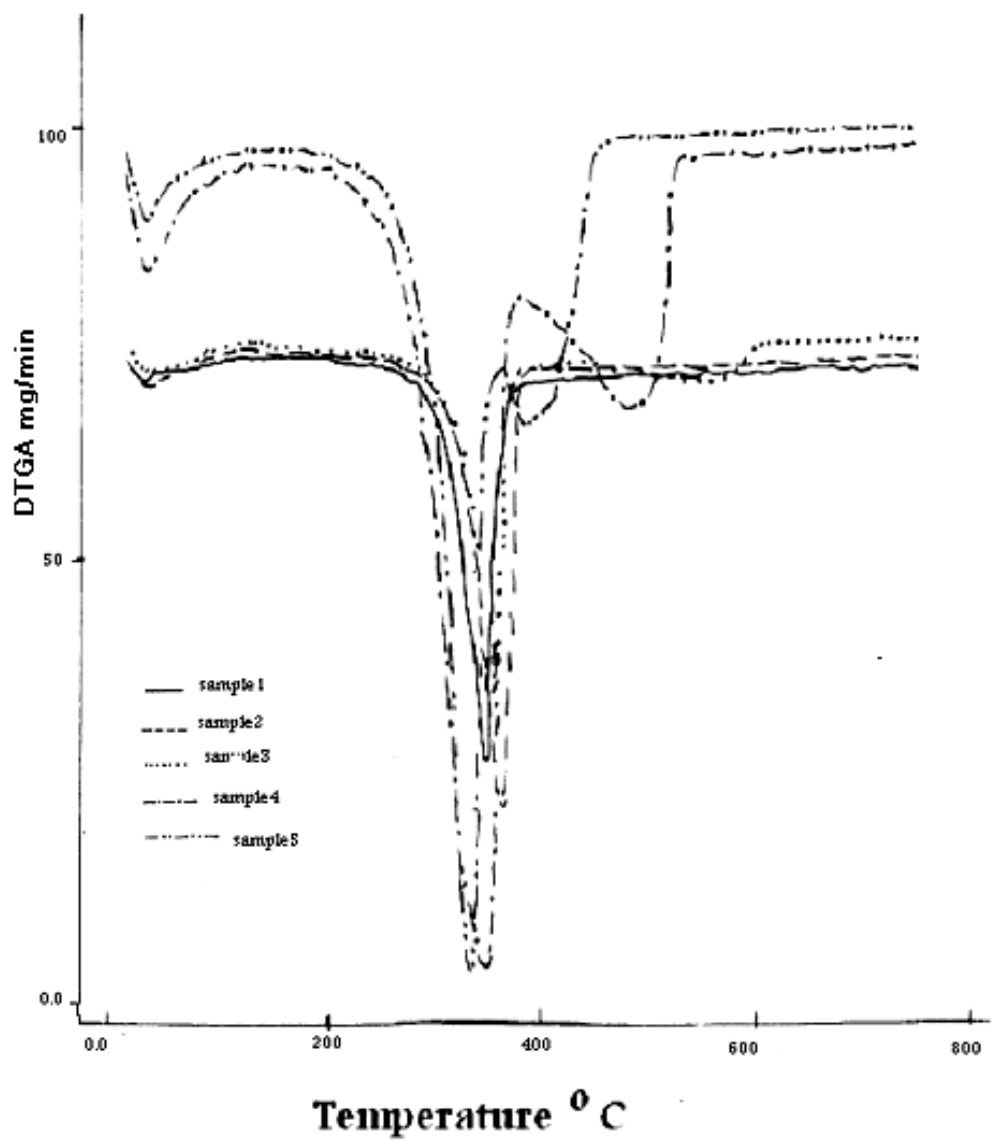

Figure 3. Recorded DTGA thermogrms of cotton fabrics

Where: sample1=blank cotton fabric undyed, sample2= blank cotton fabric dyed without mordant, sample $3=$ cotton fabric dyed with Alum, sample $4=$ cotton fabric dyed with ferrous sulfate, sample $5=$ cotton fabric dyed with Chrome. 


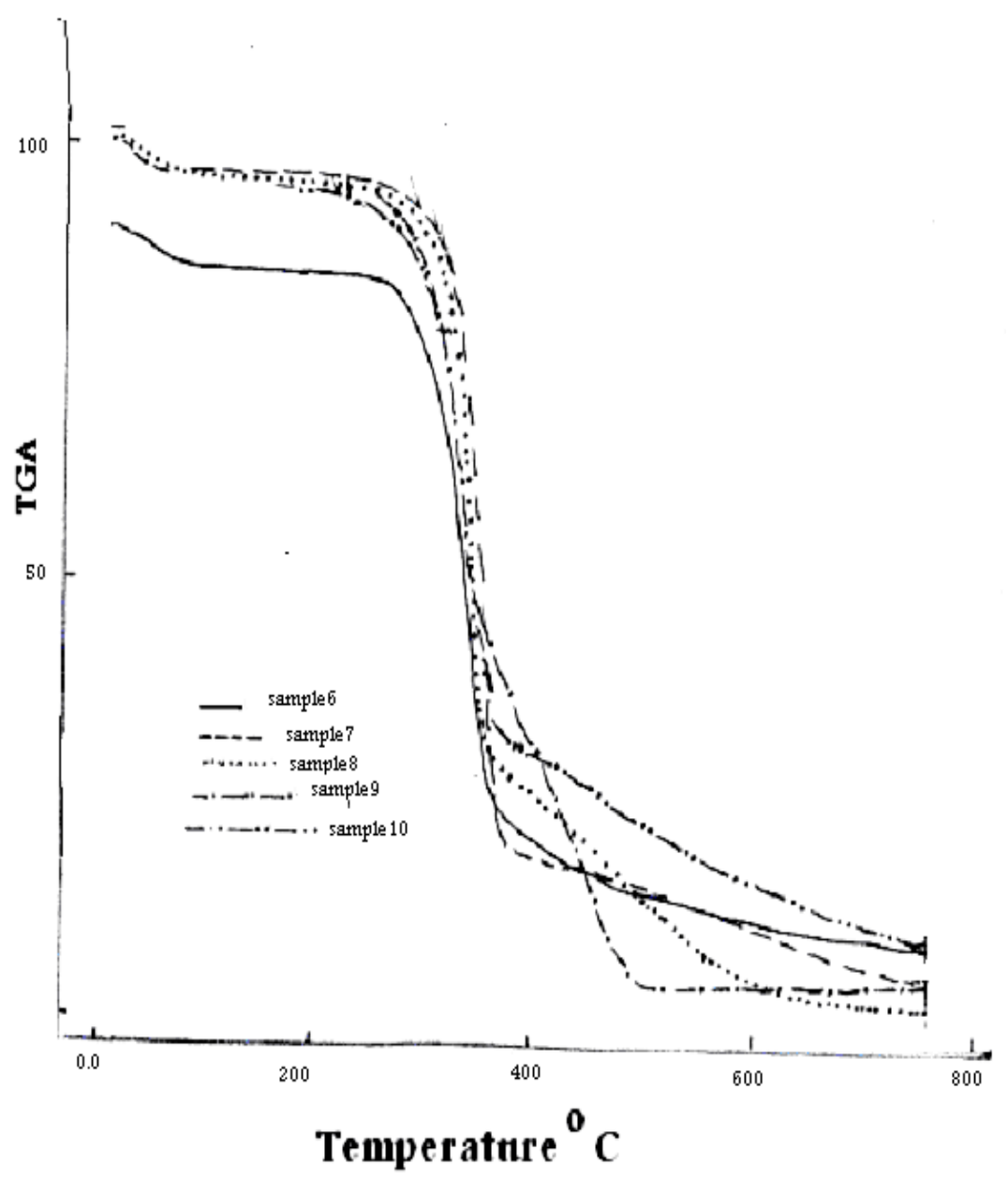

Figure 4. TGA thermograms of linen fabrics

Where: sample $6=$ blank linen fabric undyed, sample $7=$ blank linen fabric dyed without mordant, sample $8=$ linen fabric dyed with Alum, sample9= linen fabric dyed with ferrous sulfate, sample10= linen fabric dyed with Chrome. 


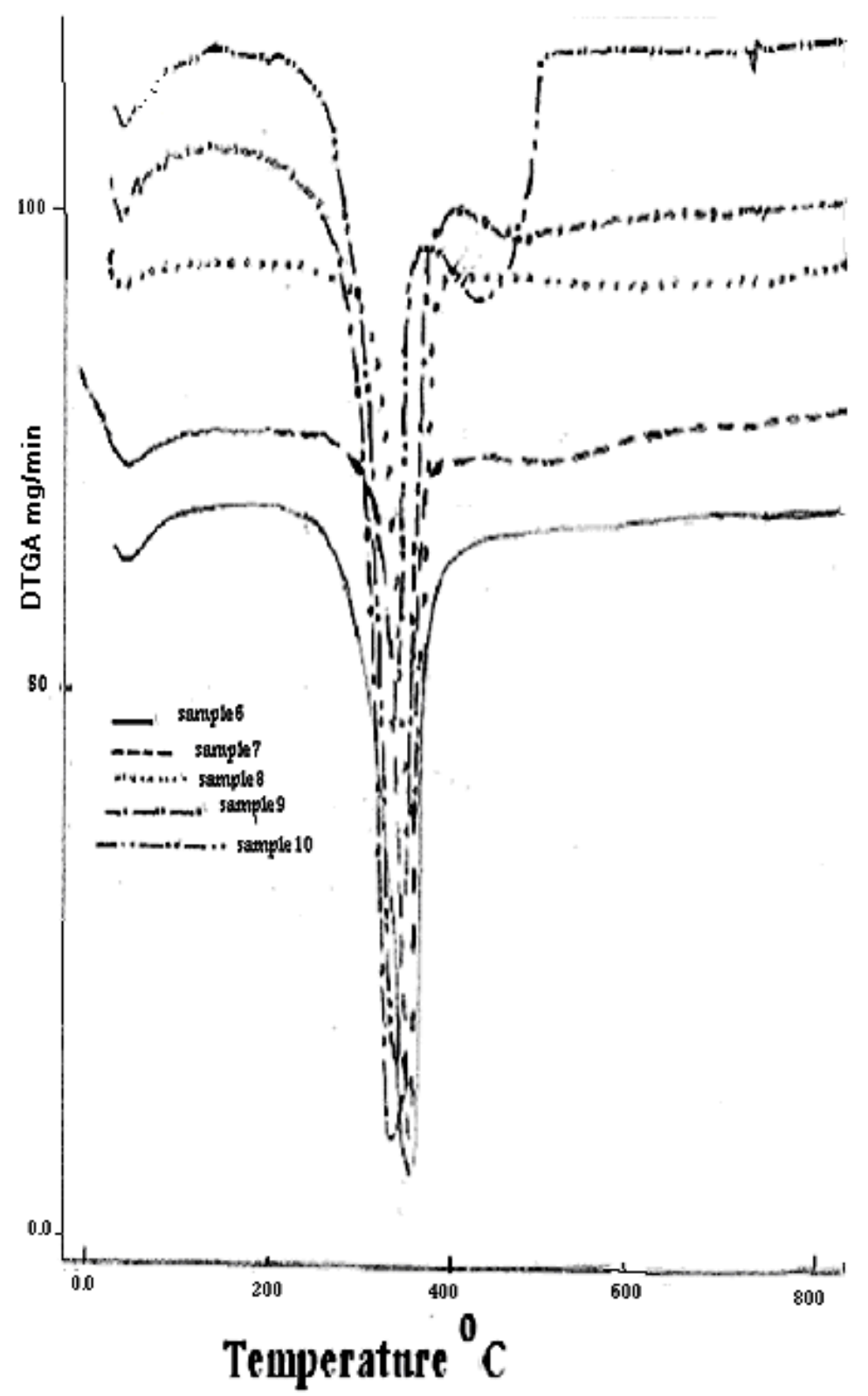

Figure 5. Recorded DTGA thermograms of linen fabrics

Where: sample $6=$ blank linen fabric undyed, sample $7=$ blank linen fabric dyed without mordant, sample $8=$ linen fabric dyed with Alum, sample9= linen fabric dyed with ferrous sulfate, sample10= linen fabric dyed with Chrome. 


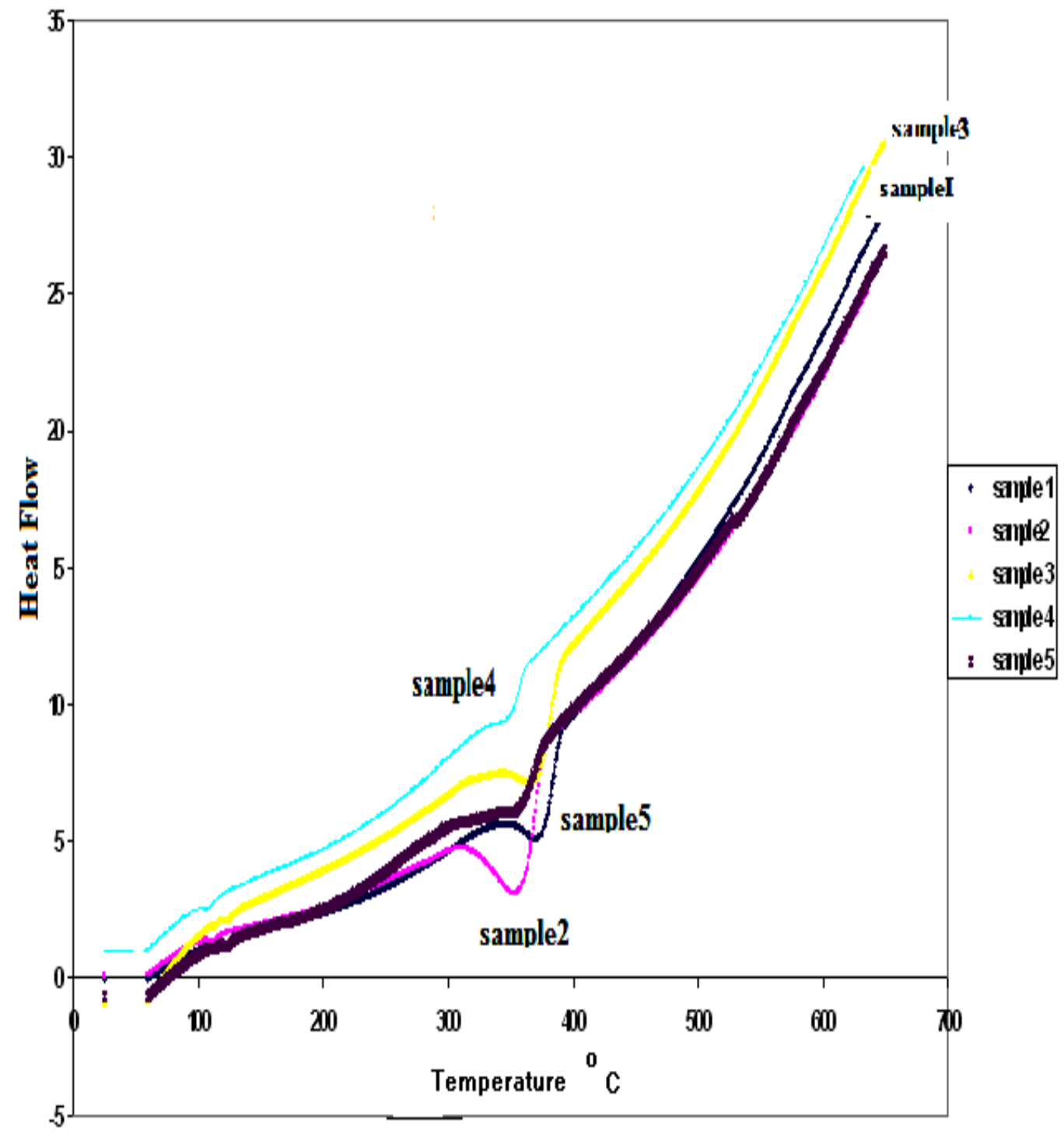

Figure 6. DSC curve of cotton fabrics

Where: sample1=blank cotton fabric undyed, sample2= blank cotton fabric dyed without mordant,sample $3=$ cotton fabric dyed with Alum, sample $4=$ cotton fabric dyed with ferrous sulfate, sample $5=$ cotton fabric dyed with Chrome. 


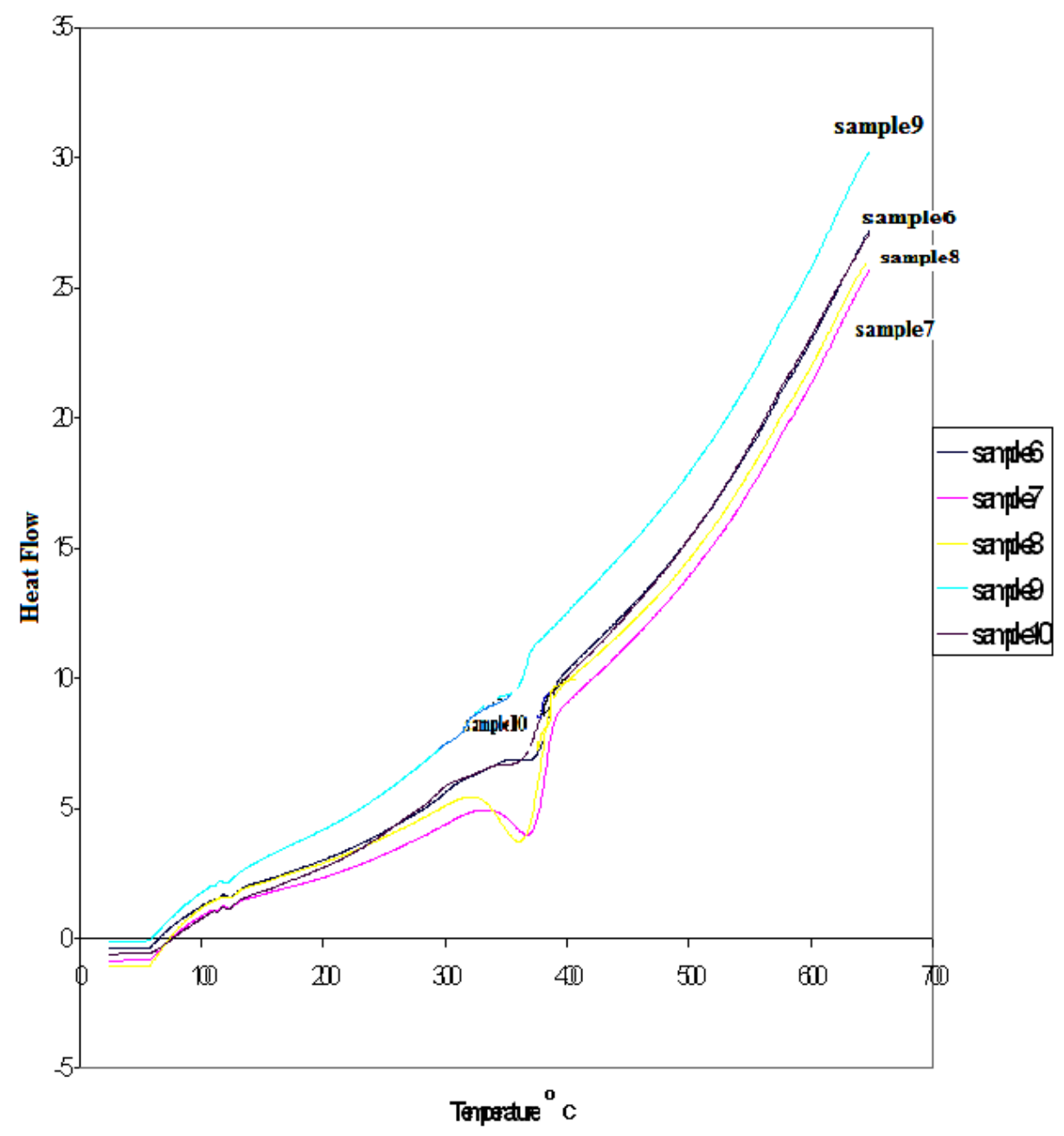

Figure 7. DSC curve of linen fabrics

Where: sample6=blank linen fabric undyed, sample7= blank linen fabric dyed without mordant, sample $8=$ linen fabric dyed with Alum, sample9= linen fabric dyed with ferrous sulfate, sample $10=$ linen fabric dyed with Chrome.

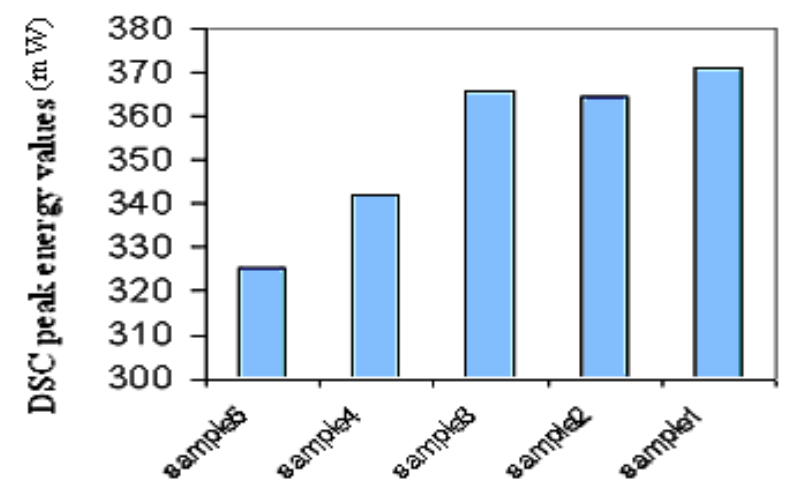

Figure 8. DSC peak energy values $(\mathrm{mW})$ of cotton fabrics

Where: sample1=blank cotton fabric undyed, sample $2=$ blank cotton fabric dyed without mordant,sample $3=$ cotton fabric dyed with Alum, sample $4=$ cotton fabric dyed with ferrous sulfate,sample $5=$ cotton fabric dyed with Chrome. 


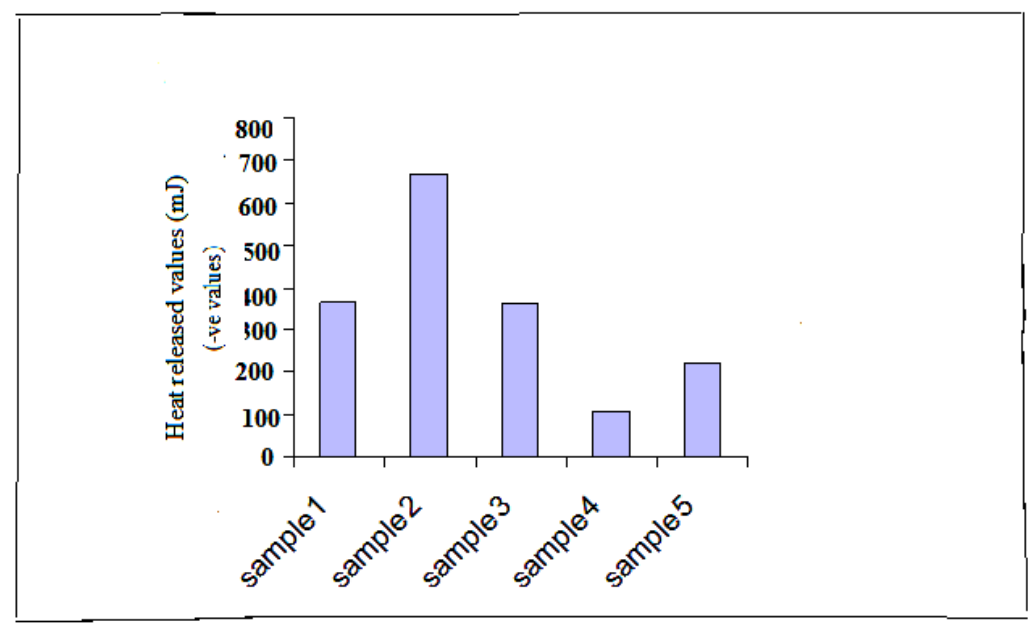

Figure 9. Heat released values $(\mathrm{mJ})$ of cotton fabrics

Where: sample1=blank cotton fabric undyed, sample $2=$ blank cotton fabric dyed without mordant,sample $3=$ cotton fabric dyed with Alum, sample $4=$ cotton fabric dyed with ferrous sulfate,sample $5=$ cotton fabric dyed with Chrome.

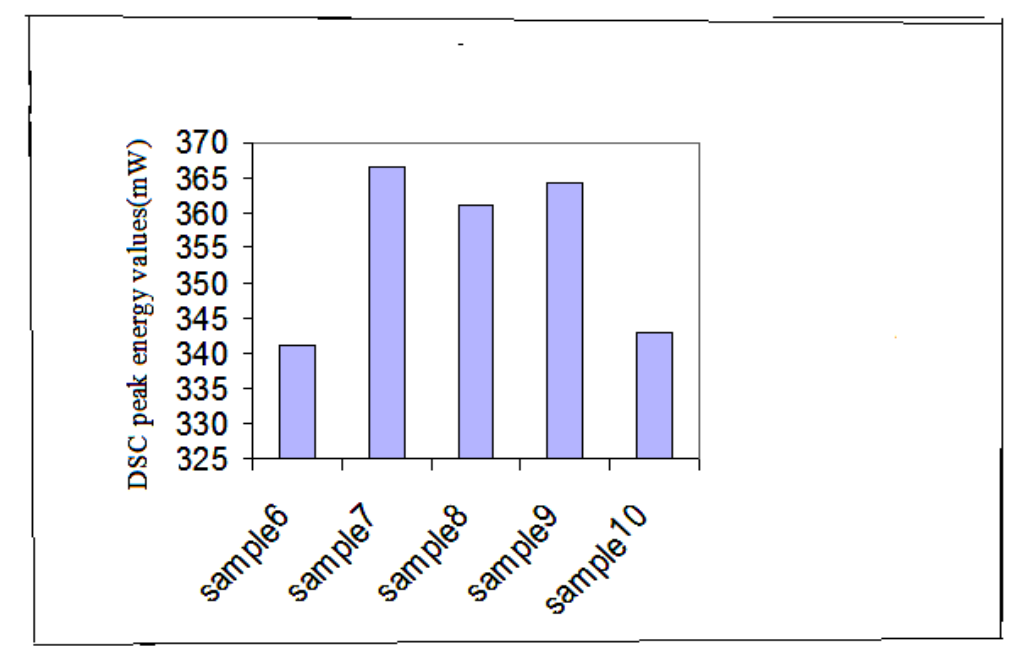

Figure 10. DSC peak energy values $(\mathrm{mW})$ of linen fabrics

Where: sample6=blank linen fabric undyed, sample $7=$ blank linen fabric dyed without mordant, sample $8=$ linen fabric dyed with Alum, sample9= linen fabric dyed with ferrous sulfate, sample $10=$ linen fabric dyed with Chrome. 


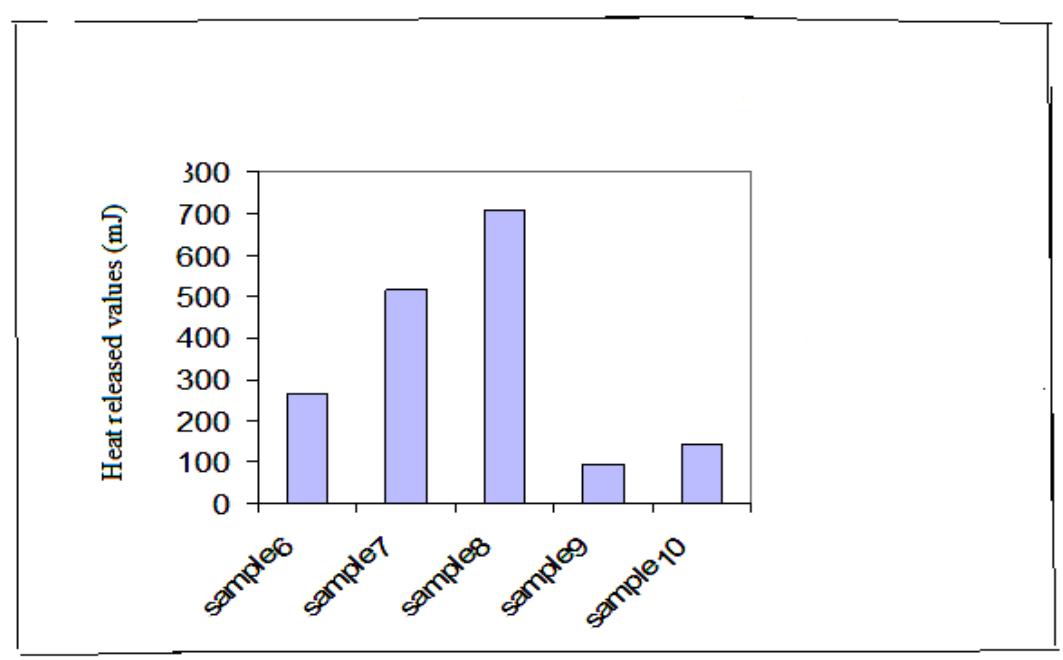

Figure 11. Heat released values (mJ) of linen fabrics

Where: sample6=blank linen fabric undyed, sample $7=$ blank linen fabric dyed without mordant, sample $8=$ linen fabric dyed with Alum, sample9= linen fabric dyed with ferrous sulfate, sample10= linen fabric dyed with Chrome. 